\title{
Antiplatelet therapy for peripheral artery disease
}

\author{
Rosetta Melfi, Elisabetta Ricottini
}

Unit of Cardiovascular Sciences, Department of Medicine, Campus Bio-Medico University of Rome, Rome, Italy

Contributions: (I) Conception and design: All authors; (II) Administrative support: All authors; (III) Provision of study materials or patients: All authors; (IV) Collection and assembly of data: All authors; (V) Data analysis and interpretation: All authors; (VI) Manuscript writing: All authors; (VII) Final approval of manuscript: All authors.

Correspondence to: Rosetta Melfi, MD. Unit of Cardiovascular Sciences, Campus Bio-Medico University of Rome, Via Alvaro del Portillo, 200 00128, Rome, Italy. Email: r.melfi@unicampus.it.

\begin{abstract}
Atherosclerotic cardiovascular (CV) disease represents one of leading cause of mortality and morbidity in Western countries. An increased risk of $\mathrm{CV}$ events was identified in patients with peripheral arterial diseases (PADs), which include all arterial diseases, other than coronary arteries and the aorta. In particular, lower extremity artery disease (LEAD) and/or carotid artery disease present growing incidence in general population and a consequent increase in mortality and morbidity. Medical treatment, including antiplatelet therapy, is a cornerstone in management of these patients, even when they are treated with endovascular or surgical procedures. Despite their clinical relevance, data on optimal antiplatelet treatment in this clinical setting are lacking and often derived from clinical trials on coronary artery disease and by subgroups analysis. The purpose of this review is to examine the available data from registries, randomized trials and meta-analysis on antiplatelet treatment in patients with LEAD and carotid stenosis with the aim to provide evidence to support clinical decision making.
\end{abstract}

Keywords: Peripheral arterial diseases (PADs); lower extremity artery disease (LEAD); carotid artery disease; antiplatelet drugs

Submitted Apr 27, 2018. Accepted for publication Jun 28, 2018.

doi: $10.21037 / \mathrm{cdt} .2018 .07 .02$

View this article at: http://dx.doi.org/10.21037/cdt.2018.07.02

\section{Introduction}

Atherosclerotic cardiovascular (CV) disease represents the most common cause of mortality and morbidity in Western countries with an estimated incidence of more than 200 million of adults affected worldwide. In this context an important, and frequently underestimated role, is played by peripheral arterial diseases (PADs), which include all arterial diseases, other than coronary arteries and the aorta. As well underlined in the latest Guidelines by the European Society of Cardiology (ESC) the term PADs should be distinguished from the term "peripheral artery disease" often used to describe lower extremity artery disease (LEAD), as this also includes the carotid and vertebral, upper extremities, mesenteric and renal arteries (1). Data derived from a recent meta-analysis estimated a prevalence of $4.2 \%$ for moderate to severe carotid artery disease. The prevalence of carotid stenosis is higher in patients older than 70 years $(6.9 \%$ in females and $12.5 \%$ in males) (2). In recent years, also a great increase in the incidence of LEAD, nearly to $23 \%$, has been registered as result of global aging, increased incidence of diabetes, and more widespread of tobacco use (3). At the same time, the rates of mortality for LEAD have grown between 1990 and 2010 in Europe, with 3.5 per 100,000 individuals in 2010 in Western Europe $(1,3)$. Both carotid artery disease and LEAD are associated with an increased risk of $\mathrm{CV}$ mortality and morbidity. Risk factors modification and the use of cardioprotective medications, as antihypertensive drugs, statin and antiplatelet medications represent the cornerstone of medical management. Nevertheless, the greatest evidence showing the benefit of antiplatelet agents in reducing recurrence of $\mathrm{CV}$ events derived from large trials on treatment of coronary artery disease (CAD). Data on antiplatelet treatment in the setting of LEAD and 
Table 1 Summary of indication on antiplatelet treatment from ESC guidelines 2017

\begin{tabular}{lcc}
\hline District involved & Monotherapy (aspirin or clopidogrel) & DAPT (aspirin plus clopidogrel) \\
\hline LEAD & Class III A & Class I A \\
Asymptomatic & From 1 month after procedure: class Ila C & For 1 month after procedure: class Ila C \\
Symptomatic & Class Ilb B & \\
Endovascular revascularization & & - \\
Surgical revascularization & Class Ila C \\
Carotid artery disease & Class I A \\
Asymptomatic (>50\% carotid artery stenosis, & From 1 month after procedure: class I A & For 1 month after procedure: class I A \\
low bleeding risk) & Class I A & - \\
Symptomatic &
\end{tabular}

ESC, European Society of Cardiology; LEAD, lower extremity.

carotid stenosis are limited and often deduced from small clinical studies. The purpose of this review is to examine the available data derived from registries, randomized trials and meta-analysis on antiplatelet treatment in patients with LEAD and carotid artery disease, with the aim to provide the evidence to support clinical decision making.

We will proceed starting from a summary of latest European guidelines indications, followed by a revision of available evidence on antiplatelet treatment. Due to the complexity in medical and interventional treatment of this arteries district, we will review in two separate sections data on LEAD and carotid stenosis.

\section{Summary of indications from European guidelines}

The latest ESC Guidelines on Diagnosis and Treatment of Peripheral Arterial Diseases have included a section on specific recommendations for antiplatelet treatment in patients with LEAD and carotid artery disease (Table 1). In the context of LEAD, one on the main new recommendations is related to the treatment of asymptomatic patients, in who antiplatelet therapy was not routinely recommended (class III, A). A single antiplatelet therapy was recommended for symptomatic, medically managed patients (class I, A), as well as for patients treated with endovascular and surgical procedures. In particular, single antiplatelet therapy with clopidogrel should be preferred over aspirin (class IIb, B). Dual antiplatelet therapy (DAPT) is recommended after infra-inguinal stenting for at least one month, even without a strong level of evidence (class IIa, C), and may be considered after surgery with prosthetic graft (class IIb, B).

Regarding patients affected by carotid artery disease evidence supporting the use of antiplatelet therapy for secondary prevention of recurrent stroke is stronger than that available for asymptomatic patients, therefore single antiplatelet treatment was in this district indicated in both asymptomatic and symptomatic patients but with different class of indications: class IA for symptomatic patients and class IIa $\mathrm{C}$ for asymptomatic patients. In the same guidelines clopidogrel $(75 \mathrm{mg} /$ day $)$ is considered an alternative in patients with aspirin intolerance. DAPT is recommend for one month after carotid artery stenting (CAS), whereas single antiplatelet therapy is continued indefinitely (class IA), in particular in patients with recent myocardial infarction (MI) and low bleeding risk. Single antiplatelet therapy with aspirin or clopidogrel is recommend as class IA indication also in patients treated with carotid endarterectomy (CEA) (Table 1).

\section{Antiplatelet treatment in LEAD}

Antiplatelet treatment in patients with LEAD is traditionally considered fundamental in order to reduce CV events, including MI, ischemic stroke, and death, as they are particularly increased in this clinical setting. Indeed, in these patients the rates for CAD localization range from 
$25 \%$ to $75 \%$ and this could explain the increased CV risk in this population (1).

LEAD may be clinically silent or may present with signs and symptoms indicative of ischemia. Symptomatic patients may exhibit various clinical presentations: atypical leg symptoms, intermittent claudication, or critical limb ischemia (CLI), characterized by ischemic rest pain, skin ulceration or gangrene. Patients with both LEAD and atherosclerotic disease in another vascular bed, diabetes, or end-stage renal disease have a higher risk for progression of disease and a worse prognosis (4). Symptomatic patients present a higher mortality rate than those with asymptomatic disease, although both have significant risk for poor CV outcomes (4-6). Aims of treatment for symptomatic patients are the relief of symptoms and the prevention of complications and $\mathrm{CV}$ events. First line treatment involves modification of lifestyle (cessation of smoke habit, dietary changes and physical activity) and medical control of $\mathrm{CV}$ risk factors (hypertension, diabetes and dyslipidemia) with antihypertensive and glucose lowering medications, statins and antithrombotic drugs (indication class I in ESC guidelines) (1). Revascularization with endovascular or surgical procedures is an option for patients who remain symptomatic despite medical treatment or present signs of CLI (7). Antiplatelet treatment is traditionally considered a key part of medical treatment in order to reduce $\mathrm{CV}$ events, but it is also a corner stone in periprocedural management in order to prevent acute thrombotic complications. Nevertheless, evidence on antiplatelet management on LEAD come from small studies or subgroups analysis. Trials specifically designed to assess efficacy of antiplatelet drugs for $\mathrm{CV}$ events risk reduction in patients with LEAD are rare. Considering the wide spectrum of patients with LEAD it would be more adequate to differentiate these data based on type of drugs and type of treatment (medical, endovascular or surgical, Tables 2-4), as proposed by a recent consensus and by the latest ESC guidelines on this topic $(1,7)$.

\section{Antiplatelet treatment in stable LEAD}

\section{Aspirin}

First line antiplatelet treatment for LEAD is monotherapy with aspirin or clopidogrel (Table 2). Previous studies supported the use of aspirin monotherapy for patients with stable LEAD. In the meta-analysis from the Antithrombotic Trialists' Collaboration, including 6,263 patients from randomized trials on antiplatelet therapy for prevention of
$\mathrm{CV}$ events, a $23 \%$ odds reduction (OR) of $\mathrm{CV}$ events was shown among patients with symptomatic LEAD (8). More recently, the CLIPS (Critical Leg Ischemia Prevention Study) trial showed a significant reduction of vascular events (including stroke, MI and pulmonary embolus) and CLI by low dose of aspirin (12 vs. 28, $\mathrm{P}=0.013$; HR $0.42,95 \%$ CI: 0.21-0.83). Of note, this latter study is a small trial on aspirin versus placebo but enrolling symptomatic high-risk patients (with Fontaine I-II LEAD) and it was prematurely stopped with only 366 patients included (9). Treatment with aspirin was not associated with an important increase in bleeding events $(\mathrm{P}=0.99)$. Conversely, the POPADAD (Prevention of Progression of Arterial Disease and Diabetes) trial enrolled 1,276 patients with diabetes and asymptomatic LEAD as detected by a lower than normal ankle brachial pressure index (ABI $\leq 0.99)$ Patients were randomized to receive aspirin or placebo. Aspirin treatment was not associated with any benefit in prevention of $\mathrm{CV}$ events and major amputation for CLI, as well as it did not increase incidence of gastrointestinal bleedings (10). These results were confirmed in 2010 by another larger randomized trial comparing aspirin versus placebo in treatment of patients with asymptomatic LEAD: aspirin did not show efficacy in prevention of $\mathrm{CV}$ events including coronary events, stroke and revascularization (HR 1.03, 95\% CI: 0.84-1.27) (11). Based on these trials efficacy of aspirin treatment seems to be relevant only in symptomatic patients, probably reflecting the higher risk of this population.

Finally, a no significant relative risk (RR) reduction for $\mathrm{CV}$ events (CV death, MI, stroke) with different doses of aspirin versus placebo was also observed in a metaanalysis of 18 randomized trials involving 5,269 patients with LEAD. However, studies included presented a wide spectrum of patients with different clinical conditions (asymptomatic, symptomatic and treated with percutaneous or surgical revascularization).

\section{Clopidogrel}

The efficacy of clopidogrel in monotherapy versus aspirin was first tested in the CAPRIE (Clopidogrel versus Aspirin in Patients at Risk of Recurrent Ischemic Events) trial. This study compared clopidogrel monotherapy versus aspirin monotherapy in secondary prevention in patients with a history of ischemic stroke, MI, or symptomatic atherosclerotic LEAD. Treatment with clopidogrel showed a significant, although marginal, $\mathrm{CV}$ risk reduction versus aspirin $(5.32 \%$ vs. $5.83 \%$ in aspirin group, $\mathrm{P}=0.043,8.7 \%$ $\mathrm{RR}$ reduction), while bleeding rates were comparable 
Table 2 Principal studies on antiplatelet treatment in stable LEAD and carotid artery disease

\begin{tabular}{|c|c|c|c|c|c|}
\hline Study name & $\begin{array}{l}\text { District } \\
\text { involved }\end{array}$ & Type of study & Study population and treatment & Primary endpoint & Main results \\
\hline \multicolumn{6}{|l|}{ Aspirin } \\
\hline POPADAD (10) & LEAD & $\begin{array}{l}\text { Randomized, } \\
\text { double blind, } 2 \times 2 \\
\text { factorial }\end{array}$ & $\begin{array}{l}1,276 \text { patients with diabetes or } \\
\text { LEAD } \\
\text { Aspirin vs. placebo; antioxidant } \\
\text { vs. placebo }\end{array}$ & $\begin{array}{l}\text { Death from coronary } \\
\text { artery disease or } \\
\text { stroke; non-fatal MI or } \\
\text { stroke; or above-ankle } \\
\text { amputation for CLI }\end{array}$ & $\begin{array}{l}18.2 \% \text { vs. } 18.3 \%, \mathrm{HR} \\
0.98(95 \% \mathrm{Cl}, 0.76-1.26)\end{array}$ \\
\hline $\begin{array}{l}\text { Aspirin for } \\
\text { Asymptomatic } \\
\text { Atherosclerosis } \\
\text { Trialists (11) }\end{array}$ & LEAD & $\begin{array}{l}\text { Randomized, } \\
\text { double blind }\end{array}$ & $\begin{array}{l}\text { 3,350 of patients with } \\
\text { asymptomatic LEAD } \\
\text { Aspirin vs. placebo }\end{array}$ & $\begin{array}{l}\text { Fatal or non-fatal } \\
\text { coronary events; stroke; } \\
\text { revascularization }\end{array}$ & $\begin{array}{l}\text { 13.7/1,000 person vs. } \\
13.3 / 1,000, \mathrm{HR} 1.03 \\
(95 \% \mathrm{Cl}, 0.84-1.27)\end{array}$ \\
\hline Berger (12) & LEAD & $\begin{array}{l}\text { Meta-analysis if } \\
\text { small trials }\end{array}$ & $\begin{array}{l}5,269 \text { patients on aspirin or } \\
\text { aspirin plus dipyridamole }\end{array}$ & CV death, MI, stroke & $\begin{array}{l}8.9 \% \text { vs. } 11 \% ; \text { RR } 0.88 \\
(95 \% \mathrm{Cl}, 0.76-1.04)\end{array}$ \\
\hline O’Donnell (13) & $\begin{array}{l}\text { Carotid } \\
\text { stenosis }\end{array}$ & $\begin{array}{l}\text { Meta-analysis of } \\
\text { various antiplatelet } \\
\text { regimen }\end{array}$ & $\begin{array}{l}9,469 \text { patients with previous } \\
\text { ischemic stroke or TIA }\end{array}$ & CV death, MI, stroke & Odds reduction $18 \%$ \\
\hline Côté (14) & $\begin{array}{l}\text { Carotid } \\
\text { stenosis }\end{array}$ & $\begin{array}{l}\text { Randomized, } \\
\text { double blind }\end{array}$ & $\begin{array}{l}372 \text { asymptomatic patients with } \\
\text { carotid stenosis of } 50 \% \text { or more }\end{array}$ & $\begin{array}{l}\text { Death, unstable angina, } \\
\text { MI, stroke, TIA }\end{array}$ & $\begin{array}{l}\mathrm{HR} 0.99(95 \% \mathrm{Cl} \\
0.67-1.46), \mathrm{P}=0.95\end{array}$ \\
\hline CARESS (17) & $\begin{array}{l}\text { Carotid } \\
\text { stenosis }\end{array}$ & $\begin{array}{l}\text { Randomized, } \\
\text { double blind }\end{array}$ & $\begin{array}{l}107 \text { patients with recently } \\
\text { symptomatic carotid stenosis } \\
\text { DAPT (aspirin plus clopidogrel) } \\
\text { versus aspirin monotherapy }\end{array}$ & $\begin{array}{l}\text { MES (asymptomatic } \\
\text { microembolic signals) } \\
\text { positive patients }\end{array}$ & $\begin{array}{l}\text { RR 39.8\% (95\% Cl, } \\
13.8-58.0 \%), P=0.0046\end{array}$ \\
\hline CHANCE (18) & $\begin{array}{l}\text { Carotid } \\
\text { stenosis }\end{array}$ & $\begin{array}{l}\text { Randomized, } \\
\text { double blind }\end{array}$ & $\begin{array}{l}5,170 \text { patients with minor } \\
\text { ischemic stroke or high-risk TIA } \\
\text { DAPT (aspirin plus clopidogrel) } \\
\text { versus aspirin monotherapy }\end{array}$ & $\begin{array}{l}\text { Stroke (ischemic or } \\
\text { hemorrhagic) during } 90 \\
\text { days of follow-up }\end{array}$ & $\begin{array}{l}8.2 \% \text { vs. } 11.7 \% ; \mathrm{HR} \\
0.68 \text { (95\% Cl, 0.57-0.8), } \\
\mathrm{P}<0.001\end{array}$ \\
\hline
\end{tabular}

Table 2 (continued) 
Table 2 (continued)

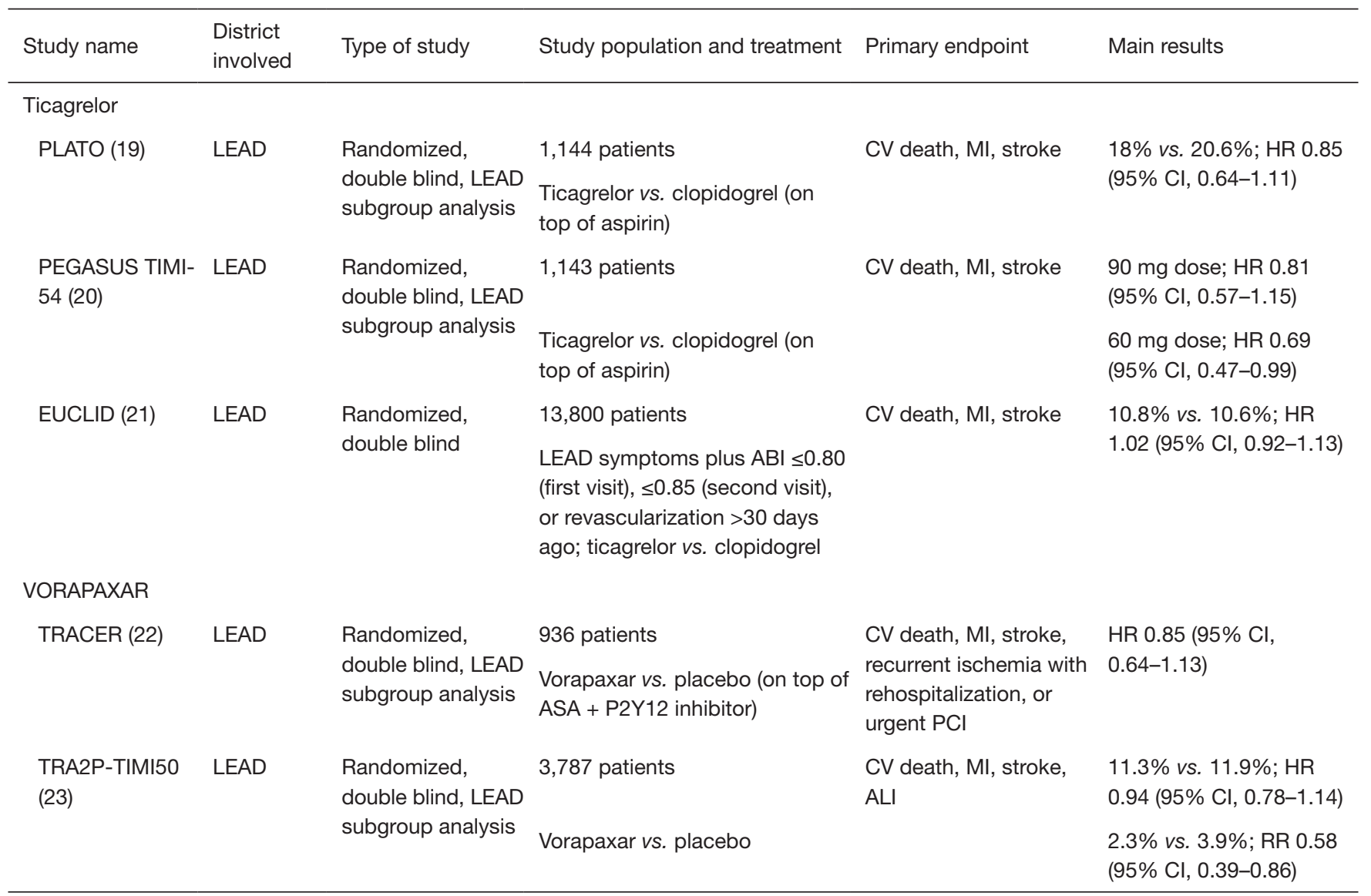

LEAD, lower extremity artery disease; CAD, coronary artery disease; CV, cardiovascular; MI, myocardial infarction; CLI, critical limb ischemia; HR, hazard ratio; RR, relative risk; TIA, transient ischemic attack; DAPT, dual antiplatelet therapy; MES, microembolic signal; $\mathrm{ABI}$, ankle brachial pressure index; ALI, acute limb ischemia.

between the two groups. To note, the risk reduction was greater in the LEAD subgroup (RR $0.76,95 \% \mathrm{CI}$ : 0.64-0.91) (15). Subsequently the efficacy of clopidogrel was tested in the context of DAPT. In the CHARISMA (Clopidogrel for High Atherothrombotic Risk and Ischemic Stabilization, Management and Avoidance) trial, there was no rate difference in composite endpoint ( $\mathrm{CV}$ death, MI, stroke) in patients treated with DAPT (aspirin plus clopidogrel) versus aspirin alone. At the same time, a nonsignificant increase in GUSTO (Global Use of Strategies to Open Occluded Coronary Arteries) severe bleeding and a significant increase in GUSTO moderate bleeding was registered in the clopidogrel treated group (35). In a posthoc analysis of CHARISMA involving 3,096 patients with LEAD, the primary endpoint (composite of $\mathrm{CV}$ death, $\mathrm{MI}$ and stroke) occurred in $7.6 \%$ of patients treated with
DAPT versus $8.9 \%$ of patients treated with aspirin (HR 0.85, 95\% CI: $0.66-1.08, \mathrm{P}=0.18$ ). The rates of severe, fatal, or moderate bleedings did not differ between the groups, whereas minor bleedings were increased with clopidogrel: $34.4 \%$ vs. $20.8 \%$ (odds ratio, 1.99 ; $95 \%$ CI: $1.69-2.34$; $\mathrm{P}<0.001)(16)$.

\section{Ticagrelor}

Evidence from studies on CAD have suggested that ticagrelor, a potent reversibly $\mathrm{P} 2 \mathrm{Y} 12$ antagonist, may add some benefits in CV events prevention. In the PLATO (Platelet Inhibition and Patient Outcomes) trial, 18,624 patients with acute coronary syndrome (ACS) were randomized to ticagrelor (180 $\mathrm{mg}$ loading dose, $90 \mathrm{mg}$ twice-daily maintenance dose) or clopidogrel (300-600 mg loading dose, $75 \mathrm{mg}$ /day maintenance dose). At 12 months, 
Table 3 Principal studies on antiplatelet treatment in endovascular revascularization in LEAD and carotid artery disease

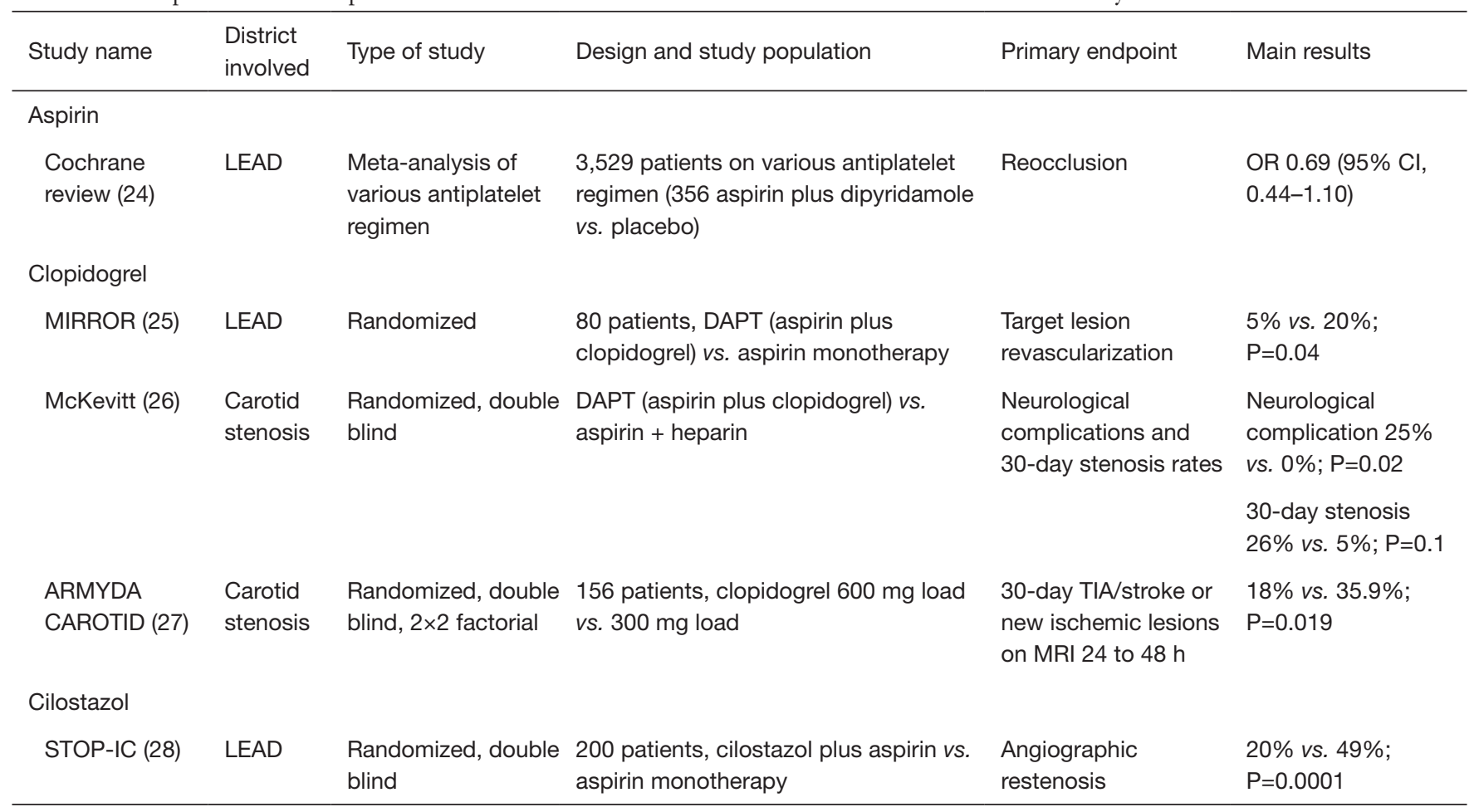

ticagrelor significantly reduced the primary composite endpoint (CV death, MI, stroke) compared with clopidogrel (9.8\% vs. $11.7 \%$, respectively; HR 0.84, 95\% CI: $0.77-$ $0.92 ; \mathrm{P}<0.001)$. Ticagrelor did not increase the rate of overall major bleeding (36). A subgroup analysis involving patients with LEAD showed a high rate of ischemic and bleeding events post-ACS. At 1-year, primary endpoint occurred in $19.3 \%$ of patients with LEAD compared to $10.2 \%$ in patients without LEAD $(\mathrm{P}<0.001)$. The benefits of ticagrelor treatment was substantially similar to those observed in general population of the study $(18 \% v s$. 20.6\%; HR 0.85, 95\% CI: 0.64-1.11; or LEAD status by treatment interaction, $\mathrm{P}=0.99)(19)$. More recently, the efficacy of prolonged DAPT with aspirin and ticagrelor was demonstrated among 21,162 high-risk patients with previous MI (1 to 3 years earlier) enrolled in the PEGASUSTIMI 54 (Prevention of Cardiovascular Events in Patients with Prior Heart Attack Using Ticagrelor Compared to Placebo on a Background of Aspirin-Thrombolysis in Myocardial Infarction 54) trial (37). A subgroup analysis involving 1,145 patients with LEAD demonstrated a $4.1 \%$ absolute risk reduction for the primary endpoint (CV death, stroke or MI) with ticagrelor (number needed to treatNNT 25), while the absolute excess of major bleeding was $0.12 \%$ (number needed to harm-NNH 834). In the same study, ticagrelor significantly reduced the risk of acute limb ischemia (ALI) or peripheral revascularization for ischemia (HR 0.65, 95\% CI: 0.44-0.95) (20). The EUCLID (Examining Use of Ticagrelor in PAD) was the latest large randomized trial focused on a purely LEAD population. This was a double-blind event driven study, which compared the efficacy of ticagrelor versus clopidogrel in 13,885 patients with symptomatic LEAD. The study included patients age $\geq 50$ years. Symptomatic LEAD was defined by (I) LEAD symptoms plus $A B I \leq 0.80$ at the first visit and $\leq 0.85$ at the second visit (43.3\%), or (II) prior lower-extremity revascularization for symptomatic LEAD >30 days ago $(56.7 \%)$. Key exclusion criteria included planned use of DAPT, requirement of aspirin, history of bleeding diathesis, treatment with anticoagulants, or poor metabolizer status for cytochrome P450 2C19 (CYP2C19) (21). The primary efficacy composite endpoint (CV death, MI, or ischemic stroke) occurred in 751 patients $(10.8 \%)$ in the ticagrelor group and in 740 patients (10.6\%) in the clopidogrel group (HR 1.02, 95\% CI: 0.92-1.13, $\mathrm{P}=0.65)$. No difference was identified in incidence of secondary endpoints (ALI and revascularization) in two groups of treatment. Major bleeding events presented 
Table 4 Principal studies on antiplatelet treatment in surgical revascularization in in LEAD and carotid artery disease

\begin{tabular}{|c|c|c|c|c|c|}
\hline Study name & $\begin{array}{l}\text { District } \\
\text { involved }\end{array}$ & Type of study & $\begin{array}{l}\text { Design and study } \\
\text { population }\end{array}$ & Primary endpoint & Main results \\
\hline \multicolumn{6}{|l|}{ Aspirin } \\
\hline $\begin{array}{l}\text { Cochrane } \\
\text { systematic } \\
\text { review }(30)\end{array}$ & LEAD & $\begin{array}{l}\text { Meta-analysis of } \\
\text { various antiplatelet } \\
\text { regimen }\end{array}$ & $\begin{array}{l}954 \text { patients, aspirin or } \\
\text { aspirin plus dipyridamole } \\
\text { vs. placebo }\end{array}$ & Graft patency & $\begin{array}{l}\text { OR } 0.42 \text { (95\% Cl, } 0.22- \\
0.83) \text {; OR } 0.19 \text { ( } 95 \% \mathrm{Cl} \text {, } \\
0.10-0.36) \text { (prosthetic graft) }\end{array}$ \\
\hline Taylor (31) & $\begin{array}{l}\text { Carotid } \\
\text { stenosis }\end{array}$ & $\begin{array}{l}\text { Randomized, } \\
\text { Double blind }\end{array}$ & $\begin{array}{l}2,849 \text { patients, different } \\
\text { aspirin doses } 81 \mathrm{mg}, 325 \\
\mathrm{mg}, 650 \mathrm{mg} \text { or } 1,300 \mathrm{mg}\end{array}$ & $\begin{array}{l}\text { CV death, MI, stroke } \\
\text { in low dose vs. high dose }\end{array}$ & 5.4 vs. $7.0 \% ; P=0.07$ \\
\hline \multicolumn{6}{|l|}{ Clopidogrel } \\
\hline $\begin{array}{l}\text { CASPAR } \\
\text { (33) }\end{array}$ & LEAD & $\begin{array}{l}\text { Randomized, } \\
\text { Double blind }\end{array}$ & $\begin{array}{l}851 \text { patients, DAPT } \\
\text { (aspirin plus clopidogrel) } \\
\text { vs. aspirin monotherapy }\end{array}$ & $\begin{array}{l}\text { Graft occlusion, ipsilateral } \\
\text { revascularization, above-ankle } \\
\text { amputation, or death at } 24 \text { months }\end{array}$ & $\begin{array}{l}\text { HR } 0.98 \text { (95\% Cl, 0.78- } \\
\text { 1.23); HR } 0.65 \text { (95\% Cl } \\
0.45-0.95) \text { (prosthetic graft) }\end{array}$ \\
\hline Payne (34) & $\begin{array}{l}\text { Carotid } \\
\text { stenosis }\end{array}$ & $\begin{array}{l}\text { Randomized, } \\
\text { Double blind }\end{array}$ & $\begin{array}{l}100 \text { patients, DAPT } \\
\text { (aspirin plus clopidogrel) } \\
\text { vs. aspirin monotherapy }\end{array}$ & $\begin{array}{l}\text { Number of emboli detected by } \\
\text { transcranial Doppler within } 3 \text { hours } \\
\text { of CEA }\end{array}$ & $\begin{array}{l}\text { OR } 10.23(95 \% \mathrm{Cl}, 1.3- \\
83.3), \mathrm{P}=0.01\end{array}$ \\
\hline
\end{tabular}

LEAD, lower extremity artery disease; OR, odds ratio; CV, cardiovascular; MI, myocardial infarction; DAPT, dual antiplatelet therapy; RR, relative risk; HR, hazard ratio; CEA, carotid endarterectomy.

similar incidence in both groups of treatment (HR 1.10, 95\% CI: 0.84-1.43, P=0.49) (21). The EUCLID have surprisingly contradicted results of subgroups analysis from coronary studies, suggesting that there is a benefit with a more potent antiplatelet therapy only in high-risk patients as those with CAD. Perhaps, current coronary antiplatelet recommendations might not be directly extended to this population, especially when these patients do not present concomitant CAD.

\section{Vorapaxar}

Vorapaxar is a novel protease activated receptor-1 antagonists. The first trial evaluating vorapaxar was the TRACER (Thrombin Receptor Antagonist for Clinical Event Reduction in Acute Coronary Syndrome) trial (38). This study enrolled 12,944 patients with ACS and at least one of the following high-risk features: age older than 55 years, previous MI, PCI or coronary artery bypass graft (CABG), diabetes, or LEAD. Patients were randomized to receive vorapaxar or placebo in addition to standard treatment with aspirin and P2Y12 inhibitor. The study was stopped by the Data and
Safety Monitoring Board for an increased rate of intracranial hemorrhage in patients treated with vorapaxar (38). In the LEAD subgroup (936 patients) the incidence of primary endpoint (CV death, $\mathrm{MI}$, or stroke) was similar in vorapaxar versus placebo. Rate of revascularization and lower extremity amputation was lower in the vorapaxar group compared to placebo $(8.1 \%$ vs. $9.0 \%, \mathrm{P}=0.016$ and $0.9 \%$ vs. $1.5 \%, \mathrm{P}=0.11$ ) (22). Vorapaxar was also tested in the TRA2PTIMI 50 (Thrombin Receptor Antagonist in Secondary Prevention of Atherothrombotic Ischemic EventsThrombolysis in Myocardial Infarction 50) trial. A total of 26,449 patients were enrolled and randomized to vorapaxar or placebo and followed for a median time of 30 months. This second study enrolled patients with stable atherosclerotic vascular disease (spontaneous MI or ischemic stroke within 2 weeks to 12 months of enrollment or LEAD with ABI less than 0.85 or previous limb ischemia). During the trial, the Data and Safety Monitoring Board recommended the interruption of treatment for patients with previous history of transient ischemic attack (TIA) or stroke for an excess in intracranial hemorrhage. The primary efficacy end-point $(\mathrm{CV}$ 
death, MI and stroke) was significantly reduced by vorapaxar (9.3\% vs. $10.5 \%$ in placebo group, $\mathrm{P}<0.001)$. This benefit was achieved at cost of an increase in bleeding rates: GUSTO moderate to severe bleedings were $4.2 \%$ with vorapaxar and $2.5 \%$ with placebo $(\mathrm{P}<0.001)$, while TIMI major and minor bleedings were $15.8 \%$ vs. $11.1 \%(\mathrm{P}<0.001)$ (39). In the subgroup analysis involving 3,787 patients with symptomatic LEAD, the primary endpoint was not different, however, the incidence of total ALI events was reduced (RR 0.59, 95\% CI, $0.38-0.93 ; \mathrm{P}=0.022$ ) (23). In particular the majority of ALI events occurred as a result of surgical graft thrombosis $(62 \%)$, followed by native vessel in situ thrombosis (25\%). Embolic events caused only $4 \%$ of ALI events, probably due to the low incidence of patients with atrial fibrillation enrolled $(\approx 5 \%)$. Even interesting interpretation of these results could be cautious and not expandable to patients asymptomatic or suffering of atrial fibrillation. Further investigations are needed before to consider the use of vorapaxar in daily practice in order to avoid ALI events.

\section{Antiplatelet treatment in endovascular revascularization}

Evidence on periprocedural antiplatelet treatment in this setting is very limited (Table 3).

Data on use of monotherapy with aspirin are very scarce and based on a recent Cochrane meta-analysis on evaluation of the effect of antiplatelet and anticoagulant drugs in prevention of restenosis and reocclusion after endovascular treatment. This meta-analysis included 22 trials for a total of 3,529 patients, but it presented the results of various antiplatelet and antithrombotic regimens (high-dose and low-dose aspirin alone or plus dipyridamole, clopidogrel, DAPT, vitamin $\mathrm{K}$ antagonist and low molecular weight heparin). At 6 months after procedure, treatment with aspirin high dose plus dipyridamole was associated with a significant reduction in reocclusion, but this was not observed with aspirin low dose. At 12 months after treatment, no significant difference in rates of reocclusion and restenosis was observed among all regimens. Data on bleeding are not reported in all trials, but they suggested a greater incidence of gastrointestinal bleeding with highdose aspirin treatment. Nevertheless, it is necessary to consider that a great part of the studies included are singlecenter small trials (24).

Data on clopidogrel are equally limited and derived from small studies. A randomized study involving only 80 patients found a benefit from DAPT (aspirin plus clopidogrel) compared to aspirin alone in reducing the target lesion revascularization 6 months after endovascular revascularization $(5 \%$ vs. $20 \%, \mathrm{P}=0.04)$. However, the benefit did not persist at 12 months ( $25 \%$ vs. $32.5 \%$, $\mathrm{P}=0.0 .35$ ). Furthermore, the study did not evaluate any $\mathrm{CV}$ events or bleeding complications (25). In the setting of endovascular procedure cilostazol was also investigated in some small randomized studies. The STOP-IC (Sufficient Treatment of Peripheral Intervention by Cilostazol) was one of the largest trials of cilostazol: it investigated whether cilostazol reduces the 12-month angiographic restenosis rate after percutaneous transluminal angioplasty with stenting for femoropopliteal lesions. A total of 200 patients were randomly assigned to receive oral aspirin with or without cilostazol. The primary endpoint was the 12 -month rate of angiographic restenosis rate. Cilostazol reduced the rate of restenosis compared to aspirin alone (20\% vs. $49 \%$, $\mathrm{P}=0.0001)$. Rates of $\mathrm{CV}$ events were similar in two groups, while the cilostazol group had a significantly higher eventfree survival at 12 months ( $83 \%$ vs. $71 \%, \mathrm{P}=0.02)$. No data on bleeding events were reported (28).

\section{Antiplatelet treatment in surgical revascularization}

In the context of surgical revascularization for LEAD, as for other treatment options, the role of aspirin was investigated in limited randomized trials (Table 4). A first study enrolling 549 patients compared the efficacy of aspirin plus dipyridamole versus placebo after saphenous vein bypass. No significant difference in graft patency between two groups of patients was observed (29). A recent Cochrane review on antiplatelet regimens after lower limb bypass surgery, suggested that aspirin (alone or plus dipyridamole) versus placebo was associated with a better primary patency at 1 year (OR $0.42,95 \%$ CI: $0.22-0.83$ ). The benefit observed was greater in the subgroup of patients treated with prosthetic bypass procedure (OR 0.19, 95\% CI: $0.10-0.36)$ (30). These data support the use of aspirin after lower limb surgical revascularization, especially in patients receiving prosthetic grafts.

Clopidogrel was tested in some trials evaluating the efficacy of a DAPT with aspirin and clopidogrel versus aspirin alone. A small study randomized 108 aspirin treated patients undergoing infrainguinal revascularization or amputation for CLI, to receive clopidogrel $(600 \mathrm{mg}$ prior to surgery, and $75 \mathrm{mg}$ daily for 3 days) or placebo. The incidence of post-procedure troponin-positive events was reduced in DAPT group (16\% vs.17.2\%; RR 0.93, 95\% CI: $0.39-2.17 ; \mathrm{P}=0.86$ ). Half of troponin-positive 
events occurred preoperatively, with clopidogrel causing a greater decline in troponin concentrations $(\mathrm{P}=0.001)$. There was no increase in major life-threatening bleedings (14\% vs. $10 \%$; RR 1.4, $95 \%$ CI: $0.49-3.76 ; \mathrm{P}=0.56$ ) and minor bleedings ( $34 \%$ vs. $21 \%$; RR $1.64,95 \%$ CI: 0.87-3.1; P=0.12) (32). The CASPAR (Clopidogrel and Acetylsalicylic Acid in Bypass Surgery for Peripheral Artery Disease) study enrolled 851 patients undergoing belowknee femoropopliteal bypass and randomized to receive DAPT or aspirin alone. The primary endpoint (composite of graft occlusion, ipsilateral revascularization, aboveankle amputation of affected limb, or death at 24 months) was similar in two groups. The subgroup of patients with prosthetic grafts (253 patients) has benefited from DAPT (HR 0.65, 95\% CI 0.45-0.95; $\mathrm{P}=0.03$ ). At the same time, the primary safety endpoint (severe bleeding following GUSTO classification) occurred more frequently in DAPT group (HR 2.84, 95\% CI: 1.32-6.08; $\mathrm{P}=0.007$ ) (33). Therefore, in surgical setting a DAPT could be reasonable in patients treated with prosthetic grafts.

\section{Antiplatelet treatment in carotid artery disease}

Antiplatelet therapy is a cornerstone in medical treatment, as it reduces the risk of embolization of the carotid plaque and stroke, both in patients with previous TIA or stroke and in asymptomatic patients with evidence of atherosclerotic carotid stenosis. Antiplatelet therapy and its indication can vary in different scenarios of carotid artery disease. Here we will review principal evidences based on clinical presentation e type of treatment of these patients (Tables 2-4).

Carotid artery disease is associated with high risk of stroke; about $20 \%$ of all strokes are related to a moderate or severe stenosis in ipsilateral internal carotid artery (40). It is crucial to distinguish symptomatic and asymptomatic patients because an important prognostic difference is associated to these different clinical settings.

Carotid stenosis is defined as symptomatic if associated with symptoms in the preceding 6 months. Clinically relevant stenosis, which increases the risk of stroke, are defined as stenosis greater than $50 \%$ (41). Graduation of severity of carotid stenosis was based on the North American Symptomatic Carotid Endarterectomy Trial (NASCET) method: a percentage of stenosis ranging from $50 \%$ to $69 \%$ identifies a moderate stenosis; a percentage between $70 \%$ and $99 \%$ is defined as severe stenosis.

CEA is effective in preventing ipsilateral ischemic events in patients with symptomatic moderate- and high-grade stenosis. The procedure is also effective in selected patients with asymptomatic stenosis.

\section{Symptomatic carotid stenosis}

The prognosis of patients with symptomatic carotid disease is significantly different from asymptomatic patients, particularly when the carotid stenosis is severe $(42,43)$. Symptomatic patients with carotid stenosis greater than $50 \%$ have a 5 -year cumulative risk $>20 \%$ for ipsilateral stroke if medically treated alone (44) and this risk is higher during the first 30 days after a TIA or minor stroke: in this range of time the risk of stroke is $27 \%$ (45).

\section{Aspirin}

The Antiplatelet Trialists' Collaboration reported that aspirin, or another single antiplatelet therapy, reduces the risk of occlusive vascular events, including stroke, in highrisk patients. In particular, non-fatal stroke was reduced by one quarter. Aspirin was the most widely studied antiplatelet drug. It was clearly demonstrated that a low dose of aspirin (75-150 $\mathrm{mg}$ daily) is at least as effective as higher daily doses. In addition, the meta-analysis showed that addition of dipyridamole to aspirin produced no significant further reduction in vascular events compared with aspirin alone (8).

About secondary prevention, a systematic review of literature suggested that aspirin alone, combination of aspirin and dipyridamole, clopidogrel, and triflusal, could reduce the relative risk of stroke after a first event. In particular, the combination of aspirin and extendedrelease dipyridamole reduces the relative odds of stroke, MI, or vascular death by about $18 \%$ (OR $0.82,95 \%$ CI: 0.74-0.91) compared with aspirin alone, without causing more bleeding event. Early administration of aspirin in the acute phase of stroke or TIA was also shown to be safe and effective (13). In the same meta-analysis, also cilostazol was proven to be effective in reduction of major vascular events when compared to placebo [4.2\% vs. $6.8 \%$ (placebo); RR 0.61, 95\% CI: 0.41-0.91] (13).

\section{Clopidogrel}

Main data supporting the use of DAPT, derived from the Clopidogrel and Aspirin for Reduction of Emboli in Symptomatic carotid stenosis (CARESS) trial and the CHARISMA trial $(17,46)$. In the CARESS trial, the efficacy of DAPT (aspirin plus clopidogrel) was compared to aspirin alone, in reducing asymptomatic embolization in patients with recently symptomatic carotid stenosis, measured 
with microembolic signals (MES) detected by transcranial Doppler ultrasound. Patients treated with DAPT had lower MESs (RR 39.8\%, 95\% CI, 13.8-58.0, P=0.0046), fewer MESs per hour (95\% CI: 31.6-78.2, $\mathrm{P}=0.0013)$, and fewer strokes compared to patients treated with aspirin alone in the first week after stroke (17).

The Clopidogrel in High-Risk Patients with Acute Nondisabling Cerebrovascular Events (CHANCE) trial is a randomized, double-blind, placebo-controlled trial conducted in China enrolling in patients with TIA or minor stroke treated within 24 hours after the onset of symptoms. The trial showed that DAPT (aspirin plus clopidogrel) was better than aspirin alone in reducing the risk of stroke in the first 90 days $(8.2 \%$ vs. $11.7 \%$; HR $0.68,95 \%$ CI: $0.57-$ $0.81, \mathrm{P}<0.001)$ and did not increase the risk of hemorrhage ( $0.3 \%$ vs. $0.3 \%, \mathrm{P}=0.73)$. There was no different incidence of moderate to severe hemorrhage in patients treated with aspirin monotherapy versus DAPT (18).

Oral anticoagulants have been shown to be less effective than antiplatelet therapy for secondary prevention of neurological events in patients with carotid atherosclerosis without a history of atrial fibrillation and therefore, it is not indicated in patients with symptoms of cerebral ischemia $(47,48)$

\section{Asymptomatic carotid stenosis}

Recent data show that asymptomatic carotid stenosis is associated to an annual risk of stroke less than $1 \%$ if optimal medical therapy is performed (49), in particular a clear decrease of risk of events was observed in the last decades, probably due to better management of risk factors and larger diffusion of optimal pharmacological treatment. There are no randomized trials demonstrating the clinical benefit of treatment with antiplatelet therapy for primary prevention of stroke in patients with $>50 \%$ carotid stenosis. Only one randomized trial evaluated the efficacy of aspirin versus placebo in patients with asymptomatic carotid artery stenosis, and it failed to show any significant longterm protective effect of aspirin therapy [11\% vs. $12.3 \%$ (placebo); HR 0.99, 95\% CI: 0.67-1.46, $\mathrm{P}=0.95)$ (14).

However, evidences supporting the use of antiplatelet therapy in primary prevention of stroke or TIA, are indirectly obtained in different trials evaluating the benefit of these drugs in primary prevention of all $\mathrm{CV}$ events, in particular in the "high-risk" population. There is a clear evidence that patients with significant carotid stenosis, even if asymptomatic for TIA or stroke, are at twice the risk of
MI (15). A meta-analysis of four primary prevention trials in "high-risk" patients demonstrated that low-dose aspirin therapy has a benefit in terms of $\mathrm{CV}$ events, including stroke, if the annual baseline risk of MI exceeds $1.5 \%$ per year (50). If the risk of CV events is high, the benefit observed in terms of reduction of ischemic events, balances the risk of bleeding and hemorrhagic stroke associated to the daily use of aspirin.

On the basis of these data different medical societies recommend aspirin in $\mathrm{CV}$ prevention for patients at high risk of $\mathrm{CV}$ events $(51,52)$ and patients with carotid artery stenosis $>50 \%$ should be treated with aspirin as part of best medical treatment (1). In any case, there is no evidence to suggest that antiplatelet agents, other than aspirin, can improve benefit in asymptomatic patients with carotid stenosis (53).

Regarding combination antiplatelet therapy, the CHARISMA study, as previously mentioned, demonstrated that DAPT did not reduce the primary endpoint of MI, stroke or, $\mathrm{CV}$ death but was associated with an increased risk of bleeding rates (46). Therefore, there is currently no evidence to support the use of DAPT in patients with asymptomatic carotid stenosis (1).

\section{Antiplatelet treatment in CAS}

About optimal antiplatelet therapy before and after CAS there are few data and management of antiplatelet therapy derived from experience in coronary angioplasty (Table 3). Current practice suggests the use of DAPT prior to and after carotid stenting $(42,54)$. Two small randomized trials comparing aspirin alone with DAPT for CAS demonstrated a higher rate of neurological events in the aspirin-alone group at 30 days $(26,55)$. In addition, data about loading dose of clopidogrel before CAS are not univocal. A little randomized study demonstrated in patients undergoing CAS that a strategy using a 600 -mg clopidogrel load before stenting protects against early ischemic cerebral events (18\% vs. $35.9 \%, \mathrm{P}=0.019$ ) (27). The optimal duration of DAPT following CAS in also unknown and there is no evidence supporting a prolonged length for DAPT $(56,57)$.

\section{Antiplatelet therapy in CEA}

Despite a proven benefit of CEA in improving outcomes of patients with symptomatic carotid stenosis, $5 \%$ to $7 \%$ of patients could present a perioperative ischemic stroke and $2-3 \%$ of patients could be affected of postoperative 
thromboembolic stroke (58). Aspirin administration in patients undergoing CEA has been shown to reduce the risk of postoperative stroke $(31,59)$ and of periprocedural MI (59). Then, aspirin should be continued before and after surgery (Table 4). A low dose of aspirin appears to be more effective then higher doses in reducing the composite of $\mathrm{CV}$ death, $\mathrm{MI}$ and stroke at 30 days $(5.4$ vs. $7.0 \%, \mathrm{P}=0.07)$ and at 3 months (6.2 vs. 8.4\%, $\mathrm{P}=0.03$ ) (31).

Payne et al. showed that in patients undergoing CEA, pretreatment with aspirin and clopidogrel before surgery reduced postoperative embolization detected by transcranial Doppler (OR 10.23, 95\% CI: 1.3-83.3, P=0.01), without increase in bleeding complications or blood transfusions (34). However, in subsequent trials, despite a benefit in neurological events after surgery, DAPT was associated with a major risk of bleeding (54). Considering that a large part of the patients undergoing CEA have a history of previous percutaneous coronary intervention (PCI) including drug-eluting stent implantation, it could be more adequate to evaluate the use of clopidogrel in association with aspirin on a case-by-case basis (53).

\section{Association with anticoagulant and future directions}

Although slightly far from the main topic of this report, which is based on antiplatelet therapy, it is useful to mention some data on association with oral anticoagulation. The WAVE (Warfarin Antiplatelet Vascular Evaluation) Trial evaluated the efficacy of combination therapy of oral anticoagulation [target international normalized ratio (INR), 2.0 to 3.0] with antiplatelet therapy compared to antiplatelet therapy alone in symptomatic patients with LEAD or carotid stenosis (60). The combination therapy was not superior to antiplatelet therapy alone (RR $0.91,95 \%$ CI: $0.74-1.12, \mathrm{P}=0.37)$. At the same time, the combination therapy was associated with an increase in life-threatening bleeding (RR 3.41, 95\% CI: 1.84-6.35, P<0.001). More recently, the approach of combination of low dose of oral anticoagulant and antiplatelet therapy was tested in the COMPASS (Cardiovascular Outcomes for People Using Anticoagulation Strategy) trial (61). The study enrolled patients with LEAD (with ABI of less than 0.9), carotid artery disease or $\mathrm{CAD}$. Patients were randomized to receive rivaroxaban (2.5 $\mathrm{mg}$ twice daily) plus aspirin (100 mg once daily) or rivaroxaban (5 $\mathrm{mg}$ twice daily) plus placebo or aspirin (100 mg once daily) plus placebo. The primary endpoint was a composite of $\mathrm{CV}$ death, $\mathrm{MI}$ or stroke; the primary peripheral endpoint was represented by major limb events, including major amputation. The incidence of primary endpoint was significantly reduced in patients treated with rivaroxaban plus aspirin versus aspirin alone ( $5 \%$ vs. $7 \%$; HR $0.72,95 \%$ CI: $0.57-0.90, \mathrm{P}=0.0047$ ), as well as major adverse limb events (1\% vs. $2 \%$; HR 0.54 , $95 \%$ CI: $0.35-0.83, \mathrm{P}=0.0037)$. No differences in the incidence of endpoints were observed in rivaroxaban alone group compared with aspirin alone group (MACE: 6\% vs. 7\%; HR 0.86, 95\% CI: 0.69-1.08, $\mathrm{P}=0.19$; limb events: $2 \%$ vs. $2 \%$; HR 0.67, 95\% CI: 0.45-1.00, $\mathrm{P}=0.5)(61)$. These results suggest a new possibility in the treatment of patients with both LEAD and carotid artery disease based on the association of low dose of antiplatelet and anticoagulant drugs. Some ongoing trials are focusing on the management of patients affected by LEAD and/or carotid stenosis, with the aim to clarify some concepts about the antiplatelet treatment. The VOYAGER PAD (Vascular Outcomes Study of Aspirin along with Rivaroxaban in Endovascular or Surgical Lim Revascularization) trial is trying to prove the efficacy and safety of rivaroxaban in reducing the risk of major thrombotic vascular events in symptomatic LEAD patients undergoing revascularization procedures. The primary endpoint is the occurrence of MI, stroke, $\mathrm{CV}$ death, ALI and major amputation (62). The ePAD (Edoxaban in Peripheral Artery Disease) is a randomized trial evaluating the efficacy and safety of adding edoxaban on top of aspirin following femoropopliteal endovascular intervention (63). The PRECISE-MRI (Prevention of Cerebral Ischaemia in Stent Treatment for Carotid Artery Stenosis-A Randomised Multi-centre Phase II Trial Comparing Ticagrelor Versus Clopidogrel With Outcome Assessment on MRI) will compare in a randomized design the efficacy of ticagrelor versus clopidogrel on top of aspirin in reducing new ischemic lesions on post-procedural MRI in patients undergoing CAS (64).

Finally, some studies will be focused on DAPT optimal duration after revascularization. The ASPIRE (Antiplatelet Strategy for Peripheral Arterial Interventions for Revascularization of Lower Extremities) will address the efficacy of clopidogrel on the background of lowdose aspirin treatment for a clinically indicated duration versus 12 months in patients undergoing endovascular treatment. The primary endpoint is the rate of primary patency, limb salvage, MI, stroke and survival (65). The LONGDAPTPAD (Effect of Prolonged DAPT after Lower Extremity Percutaneous Transluminal Angioplasty in Patients with LE-PAD) will compare the efficacy of 
3 months DAPT versus 12 months (66).

\section{Conclusions}

While antiplatelet strategies in patients with CAD are well established and based on results of large randomized trials and registries, the optimal antiplatelet management of patients with PADs is not well defined and recommendations from guidelines are rarely based on large studies. The lack of solid evidence in this field has resulted in a gap of knowledge. This is particularly prominent in the context of percutaneous revascularization, where most indications are guided by PCI recommendations. However, treatment strategies that have proven effective in patients with contemporary CAD and PADs have not always maintained this efficacy in the treatment of patients with isolated PADs. Another issue is related to the extreme variability of PADs scenarios: stable and unstable conditions, different treatment options (medical, endovascular and surgical), variable extension and localization of artery disease. Therefore, it is difficult to identify "one fits all" treatment and further trials specifically focused on different subsets of populations are needed to define the best antiplatelet management in these clinical settings.

\section{Acknowledgements}

None.

\section{Footnote}

Conflicts of Interest: The authors have no conflicts of interest to declare.

\section{References}

1. Aboyans V, Ricco JB, Bartelink MEL, et al. 2017 ESC Guidelines on the Diagnosis and Treatment of Peripheral Arterial Diseases, in collaboration with the European Society for Vascular Surgery (ESVS): Document covering atherosclerotic disease of extracranial carotid and vertebral, mesenteric, renal, upper and lower extremity arteries Endorsed by: the European Stroke Organization (ESO)The Task Force for the Diagnosis and Treatment of Peripheral Arterial Diseases of the European Society of Cardiology (ESC) and of the European Society for Vascular Surgery (ESVS). Eur Heart J 2018;39:763-816.

2. de Weerd M, Greving JP, de Jong AW, et al. Prevalence of asymptomatic carotid artery stenosis according to age and sex: systematic review and metaregression analysis. Stroke 2009;40:1105-13.

3. Fowkes FG, Rudan D, Rudan I, et al. Comparison of global estimates of prevalence and risk factors for peripheral artery disease in 2000 and 2010: a systematic review and analysis. Lancet 2013;382:1329-40.

4. Ward R, Long C, Patel MR, et al. Antithrombotic therapy in peripheral artery disease: a review of the EUCLID trial results and current ongoing trials. Clin Cardiol 2018;41:137-43.

5. Sigvant B, Hasvold P, Kragsterman B, et al. Cardiovascular outcomes in patients with peripheral arterial disease as an initial or subsequent manifestation of atherosclerotic disease: results from a Swedish nationwide study. J Vasc Surg 2017;66:507-14.e1.

6. Diehm C, Allenberg JR, Pittrow D, et al. German Epidemiological Trial on Ankle Brachial Index Study Group. Mortality and vascular morbidity in older adults with asymptomatic versus symptomatic peripheral artery disease. Circulation 2009;120:2053-61.

7. Hess CN, Norgren L, Ansel GM, et al. A Structured Review of Antithrombotic Therapy in Peripheral Artery Disease with a Focus on Revascularization: A TASC (InterSociety Consensus for the Management of Peripheral Artery Disease) Initiative. Circulation 2017;135:2534-55.

8. Antithrombotic Trialists' Collaboration. Collaborative meta-analysis of randomised trials of antiplatelet therapy for prevention of death, myocardial infarction, and stroke in high risk patients. BMJ 2002;324:71-86.

9. Catalano M, Born G, Peto R, et al. Prevention of serious vascular events by aspirin amongst patients with peripheral arterial disease: randomized, double-blind trial. J Intern Med 2007;261:276-84.

10. Belch J, MacCuish A, Campbell I, et al. Prevention of Progression of Arterial Disease and Diabetes Study Group; Diabetes Registry Group; Royal College of Physicians Edinburgh. The prevention of progression of arterial disease and diabetes (POPADAD) trial: factorial randomised placebo-controlled trial of aspirin and antioxidants in patients with diabetes and asymptomatic peripheral arterial disease. BMJ 2008;337:a1840.

11. Fowkes FG, Price JF, Stewart MC, et al. Aspirin for prevention of cardiovascular events in a general population screened for a low ankle brachial index: a randomized controlled trial. JAMA 2010;303:841-8.

12. Berger JS, Krantz MJ, Kittelson JM, et al. Aspirin for the prevention of cardiovascular events in patients with 
peripheral artery disease: a meta-analysis of randomized trials. JAMA 2009;301:1909-19.

13. O’Donnell MJ, Hankey GJ, Eikelboom JW. Antiplatelet therapy for secondary prevention of noncardioembolic ischemic stroke: a critical review. Stroke 2008;39:1638-46.

14. Côté R, Battista RN, Abrahamowicz M, et al. Lack of effect of aspirin in asymptomatic patients with carotid bruits and substantial carotid narrowing. The Asymptomatic Cervical Bruit Study Group. Ann Intern Med 1995;123:649-55.

15. CAPRIE Steering Committee. A randomised, blinded, trial of clopidogrel versus aspirin in patients at risk of ischaemic events (CAPRIE). Lancet 1996;348:1329-39.

16. Cacoub PP, Bhatt DL, Steg PG, et al. Patients with peripheral arterial disease in the CHARISMA trial. Eur Heart J 2009;30:192-201.

17. Markus HS, Groste DW, Kaps M, et al. Dual antiplatelet therapy with clopidogrel and aspirin in symptomatic carotid stenosis evaluated using doppler embolic signal detection: the Clopidogrel and Aspirin for Reduction of Emboli in Symptomatic Carotid Stenosis (CARESS) trial. Circulation 2005;111:2233-40.

18. Wang Y, Wang Y, Zhao X, et al. Clopidogrel with aspirin in acute minor stroke or transient ischemic at- tack. $\mathrm{N}$ Engl J Med 2013;369:11-9.

19. Patel MR, Becker RC, Wojdyla DM, et al. Cardiovascular events in acute coronary syndrome patients with peripheral arterial disease treated with ticagrelor compared with clopidogrel: Data from the PLATO Trial. Eur J Prev Cardiol 2015;22:734-42.

20. Bonaca MP, Bhatt DL, Storey RF, et al. Ticagrelor for prevention of ischemic events after myocardial infarction in patients with peripheral artery disease. J Am Coll Cardiol 2016;67:2719-28.

21. Hiatt WR, Fowkes FG, Heizer G, et al. Ticagrelor versus clopidogrel in symptomatic peripheral artery disease. $\mathrm{N}$ Engl J Med 2017;376:32-40.

22. Jones WS, Tricoci P, Huang Z, et al. Vorapaxar in patients with peripheral artery disease and acute coronary syndrome: insights from Thrombin Receptor Antagonist for Clinical Event Reduction in Acute Coronary Syndrome (TRACER). Am Heart J 2014;168:588-96.

23. Bonaca MP, Gutierrez JA, Creager MA, et al. Acute limb ischemia and outcomes with vorapaxar in patients with peripheral artery disease: results from the Trial to Assess the Effects of Vorapaxar in Preventing Heart Attack and Stroke in Patients With Atherosclerosis-Thrombolysis in Myocardial Infarction 50 (TRA2 ${ }^{\circ}$ P-TIMI 50). Circulation
2016;133:997-1005.

24. Robertson L, Ghouri MA, Kovacs F, et al. Antiplatelet and anticoagulant drugs for prevention of restenosis/ reocclusion following peripheral endovascular treatment. Cochrane Database Syst Rev 2012;8:CD002071.

25. Strobl FF, Brechtel K, Schmehl J, et al. Twelve-month results of a randomized trial comparing mono with dual antiplatelet therapy in endovascularly treated patients with peripheral artery disease. J Endovasc Ther 2013;20:699-706.

26. McKevitt FM, Randall MS, Cleveland TJ, et al. The benefits of combined anti-platelet treatment in carotid artery stenting. Eur J Vasc Endovasc Surg 2005;29:522-7.

27. Patti G, Tomai F, Melfi R, et al. Strategies of clopidogrel load and atorvastatin reload to prevent ischemic cerebral events in patients undergoing protected carotid stenting. Results of the randomized ARMYDA-9 CAROTID (Clopidogrel and Atorvastatin Treatment During Carotid Artery Stenting) study. J Am Coll Cardiol 2013;61:1379-87.

28. Iida O, Yokoi H, Soga Y, et al. Cilostazol Reduces Angiographic Restenosis After Endovascular Therapy for Femoropopliteal Lesions in the Sufficient Treatment of Peripheral Intervention by Cilostazol Study. Circulation 2013;127:2307-15.

29. McCollum C, Alexander C, Kenchington G, et al. Antiplatelet drugs in femoropopliteal vein bypasses: a multicenter trial. J Vasc Surg 1991;13:150-61.

30. Bedenis R, Lethaby A, Maxwell H, et al. Antiplatelet agents for preventing thrombosis after peripheral arterial bypass surgery. Cochrane Database Syst Rev 2015;2:CD000535.

31. Taylor DW, Barnett HJM, Haynes RB, et al. Low-dose and high-dose acetylsalicylic acid for patients undergoing carotid endarterectomy: a randomised controlled trial. ASA and Carotid Endarterectomy (ACE) Trial Collaborators. Lancet 1999;353:2179-84.

32. Burdess A, Nimmo AF, Garden OJ, et al. Randomized controlled trial of dual antiplatelet therapy in patients undergoing surgery for critical limb ischemia. Ann Surg 2010;252:37-42.

33. Belch JJ, Dormandy J, CASPAR Writing Committee, et al. Results of the randomized, placebo-controlled clopidogrel and acetylsalicylic acid in bypass surgery for peripheral arterial disease (CASPAR) trial. J Vasc Surg 2010;52:825-33.

34. Payne DA, Jones CI, Hayes PD, et al. Beneficial effects of clopidogrel com- bined with aspirin in reducing cerebral emboli in patients undergoing carotid endarterectomy. 
Circulation 2004;109:1476-81.

35. Bhatt DL, Fox KA, Hacke W, et al. Clopidogrel and aspirin versus aspirin alone for the prevention of atherothrombotic events. N Engl J Med 2006;354:1706-17.

36. Wallentin L, Becker RC, Budaj A, et al. Ticagrelor versus clopidogrel in patients with acute coronary syndromes. $\mathrm{N}$ Engl J Med 2009;361:1045-57.

37. Bonaca MP, Bhatt DL, Cohen M, et al. Long-term use of ticagrelor in patients with prior myocardial infarction. $\mathrm{N}$ Engl J Med 2015;372:1791-800.

38. Tricoci P, Huang Z, Held C, et al. Thrombin-receptor antagonist vorapaxar in acute coronary syndromes. N Engl J Med 2012;366:20-33.

39. Morrow DA, Braunwald E, Bonaca MP, et al. Vorapaxar in the secondary prevention of atherothrombotic events. $\mathrm{N}$ Engl J Med 2012;366:1404-13.

40. Paciaroni M, Silvestrelli G, Caso V, et al. Neurovascular territory involved in different etiological subtypes of ischemic stroke in the Perugia Stroke Registry. Eur J Neurol 2003;10:361-5.

41. Wolff T, Guirguis-Blake J, Miller T, et al. Screening for carotid artery ste- nosis: an update of the evidence for the US Preventive Services Task Force. Ann Intern Med 2007;147:860-70.

42. Ritter JC, Tyrrell MR. The current management of carotid atherosclerotic disease: who, when and how? Interact Cardiovasc Thorac Surg 2013;16:339-46.

43. Touzé E. Treatment of carotid stenosis. Curr Vasc Pharmacol 2012;10:734-8.

44. Rothwell PM, Eliasziw M, Gutnikov SA, et al. Endarterectomy for symptomatic carot- id stenosis in relation to clinical subgroups and timing of surgery. Lancet 2004;363:915-24.

45. Fairhead JF, Mehta Z, Rothwell PM. Population-based study of delays in carotid imaging and surgery and the risk of recurrent stroke. Neurology 2005;65:371-5.

46. Bhatt DL, Flather MD, Hacke $W$, et al. Patients with prior myocardial infarction, stroke, or symptomatic peripheral arterial disease in the CHARISMA trial. J Am Coll Cardiol 2007;49:1982-8.

47. Mohr JP, Thompson JL, Lazar RM, et al. A comparison of warfarin and aspirin for the prevention of recurrent ischemic stroke. N Engl J Med 2001;345:1444-51.

48. Halkes PH, van Gijn J, Kappelle LJ, et al. Medium intensity oral anticoagulants versus aspirin after cerebral ischemia of arterial origin (ESPRIT): a randomised controlled trial. Lancet Neurol 2007;6:115-24.

49. Abbott AL. Medical (nonsurgical) intervention alone is now best for prevention of stroke associated with asymptomatic severe carotid stenosis: results of a systematic review and analysis. Stroke 2009;40:e573-83.

50. Patrono C, Garcia Rodriguez LA, et al. Low-dose aspirin for the prevention of atherothrombosis. N Engl J Med 2005;353:2373-83.

51. Wolff T, Miller T, Ko S. Aspirin for the primary prevention of cardiovascular events: an update of the evidence for the US Preventive Services Task Force. Ann Intern Med 2009; 150:405-10.

52. Goldstein LB, Bushnell CD, Adams RJ, et al. Guidelines for the primary prevention of stroke: a guideline for healthcare professionals from the American Heart Association/American Stroke Association. Stroke 2011;42:517-84.

53. Ricotta JJ, AbuRahma A, Ascher E, et al. Updated Society for Vascular Surgery guidelines for management of extracranial carotid disease. J Vasc Surg 2011;54:e1-31.

54. McKinsey JF. Symptomatic carotid stenosis: endarterectomy, stenting, or best medical management? Semin Vasc Surg 2008;21:108-14.

55. Dalainas I, Nano G, Bianchi P, et al. Dual antiplatelet regime versus acetyl-acetic acid for carotid artery stenting. Cardiovasc Intervent Radiol 2006;29:519-21.

56. Lovrencic-Huzjan A, Rundek T, Katsnelson M. Recommendations for management of patients with carotid stenosis. Stroke Res Treat 2012;2012:175869.

57. Chaturvedi S, Yadav JS. The role of antiplatelet therapy in carotid stenting for ischemic stroke prevention. Stroke 2006;37:1572-7.

58. Barnett HJM, Taylor DW, Eliasziw $M$ et al. Benefit of carotid endarterectomy in patients with symptomatic moderate or severe stenosis. N Engl J Med 1998;339:1415-25.

59. Merritt JC, Bhatt DL. The efficacy and safety of perioperative antiplatelet therapy. J Thromb Thrombolysis 2004;17:21-7.

60. Anand S, Yusuf S, Xie C, et al. Oral anticoagulant and antiplatelet therapy and peripheral arterial disease. N Engl J Med 2007;357:217-27.

61. Anand SS, Bosch J, Eikelboom JW, et al. Rivaroxaban with or without aspirin in patients with stable peripheral or carotid artery disease: an international, randomised, double-blind, placebo-controlled trial. Lancet 2018;391:219-29.

62. Efficacy and Safety of Rivaroxaban in Reducing the Risk of Major Thrombotic Vascular Events in Subjects with Symptomatic Peripheral Artery Disease Undergoing 
Peripheral Revascularization Procedures of the Lower Extremities (VOYAGER PAD). Accessed 7 March, 2018. Available online: https://clinicaltrials.gov/ct2/show/ NCT02504216

63. Edoxaban in Peripheral Arterial Disease (ePAD). Accessed 7 March, 2018. Available online: https://clinicaltrials. gov/ ct2/show/study/NCT01802775

64. Prevention of Cerebral Ischaemia in Stent Treatment for Carotid Artery Stenosis - A Randomised Multi-centre Phase II Trial Comparing Ticagrelor Versus Clopidogrel With Outcome Assessment on MRI (PRECISE-MRI).

Cite this article as: Melfi R, Ricottini E. Antiplatelet therapy for peripheral artery disease. Cardiovasc Diagn Ther 2018;8(5):663-677. doi:10.21037/cdt.2018.07.02
Accessed 7 March, 2018. Available online: https:// clinicaltrials.gov/ct2/show/NCT02677545

65. Antiplatelet Strategy for Peripheral Arterial Interventions for Revascularization of Lower Extremities (ASPIRE). Accessed 7 March, 2018. Available online: https:// clinicaltrials.gov/ct2/show/NCT02217501

66. Evaluation of Short Versus Long Duration Dual Antiplatelet Therapy in Patients Undergoing Lower Extremity Endovascular Revascularization. Accessed 7 March, 2018. Available online: https://clinicaltrials.gov/ ct2/show/NCT02433587 